\section{ECONOMICS}

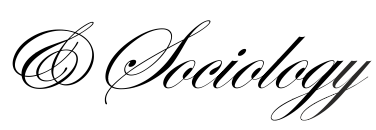

Strielkowski, W., \& Chigisheva, O. (2018). Research functionality and academic publishing: Gaming with altmetrics in the digital age. Economics and Sociology, 11(4), 306-316. doi:10.14254/2071-789X.2018/11-4/20

\title{
RESEARCH FUNCTIONALITY AND ACADEMIC PUBLISHING: GAMING WITH ALTMETRICS IN THE DIGITAL AGE
}

\author{
Wadim Strielkowski \\ University of California, Berkeley \\ Berkeley, United States \\ E-mail: \\ strielkowski@berkeley.edu \\ Oksana Chigisheva \\ Southern Federal University, \\ Rostov-on-Don, Russian \\ Federation \\ e-mail: opchigisheva@sfedu.ru
}

Received: August, 2018

1st Revision: October, 2018

Accepted: November, 2018

DOI: $10.14254 / 2071-$

789X.2018/11-4/20

JEL Classification: A12,
B00, C02

\begin{abstract}
This paper aims at introducing and testing the novel measures of research functionality and efficiency from the point of view of internationalization of academic publishing and introduction of global research career paths in the digital epoch. We analyse the recent trends in research productivity and academic publishing and scrutinize the novelties such as PlumX and Publons. Moreover, we tackle the issue of gaming with altmetrics using new digital technologies. Apart from that, we focus on the world's two most prestigious journal indexation databases, Scopus and Web of Science, and demonstrate how academic productivity might differ across academic fields and countries using their data and analytical tools. Our results might be helpful and useful in finding connections and links between research functionality, efficiency and classifications of academic productivity yielded in published research output (such as the number of papers, books, or book chapters calibrated by the impact factor (IF) or Scopus journal ranking (SJR)). The outcomes of our research would be of a special importance for bibliometricians, librarians, research policy specialists, and other global research, education, and academic stakeholders.
\end{abstract}

Keywords: research productivity, career development, internationalization, efficiency, academic publishing

\section{Introduction}

Research functionality and academic publishing is keeping up with the digital age. Academic papers are read online and shared via social networks. Scientists are competing in the number of citations and various indices (such as h-index representing the number of citations for the most cited ranked papers or i10-index that shown the number of papers cited at least 10 times) that can be checked anytime and anywhere (as soon as the Internet connection is available) and are routinely applied by the governments to measure the scientific output per invested research funds. In short, research functionality and efficiency nowadays are becoming an integral part of the established academic leadership (Chigisheva et al., 2017; Valickas et al., 2017; Jankurov et al., 2017; or Strielkowski \& Chigisheva, 2018). 
Moreover, research papers and journal articles are also pirated online just like the songs and latest Hollywood films used to be pirated two decades ago using Napster and torrents as the knowledge of digital technologies becomes very common and widespread (Himmelstein et al., 2018). One no longer needs to be a programmer or a hacker to bypass paid access to online research databases. A good example of that was the Internet portal for downloading pirated papers from research journals called Sci-Hub. Created by the unknown activist and programmer from Kazakhstan Alexandra Elbakian, it became a serious threat for the large academic publishers, but, in the same time, it can also pave the road for the subscription-based access to publishing databases (Strielkowski, 2017).

Recent developments in scientific environment that are marked by the growing importance of scientometrics and academic research databases envisaged to measure the productivity and output of academics went hand in hand with the development of online resources and social networks (Agarwal et al., 2016; Starbuck and Purtee, 2017; Ortega, 2018). The rise of Internet enabled constant verification of various research metrics (such as the hindex already mentioned above or the total number of citations) and therefore became a measure of the weight and importance of each and every academic regardless of the affiliation and geographical location.

However, one can see that these developments are coupled with such issues as academic nepotism (Brogaard et al., 2014), guest authorship, and other disputable practices that discourage young scientists from further pursuing their careers in the academia (Brotherton et al., 2018).

This paper focuses on the issues of research functionality and academic publishing in the turbulent 21 st century. We are particularly interested in analysing and evaluating various altmetrics that are getting popular quite recently. The paper is organized as follows: Section 1 provides a literature review compiled under the slogan "publish or perish". Section 2 discusses some novelties in the field of bibliometrics, namely PlumX and Publons, and contemplates over their overall functionality. Section 3 discusses some additional measures of academic productivity using the available data for countries and specific research institutions in a crosscountry and cross-sectional analysis. Section 5 outlines some implications for the future concerning the so-called "Plan S". Finally, Section 5 provides overall conclusions and policy implications.

\section{Literature review: Publish or perish}

In 1982, two American psychologists Stephen Ceci and Douhlas Peters made an experiment. They selected 13 recently published articles that appeared in top journals of psychology. Each of these articles had been written by an academic affiliated with one of the most prestigious U.S. universities (e.g., Illinois, Harvard, Stanford, or Yale). Subsequently, they changed the names and affiliations of the authors and the names of the papers and re-submitted them to the same top psychological journals. Only 3 papers were detected while the rest were peer-reviewed and rejected by the same journals that published them recently (Ceci and Peters, 1982). Of course, the experiment was intended to demonstrate the subjectivity of peer review process but it also makes us to realize that similar experiments are not going to be possible in the age of Internet when each and every journal editor immediately checks every submitted paper both of plagiarism using an inbuilt antiplagiarism software, and runs a check of authors using some journal abstract and citation database.

With regard to the above, the following question arises: How to tell a good research from a bad one? And how to tell which academic is more productive and therefore deserves career promotions or research funding? One can probably measure the scientific and research 
productivity by the number of patents and licences, or the sums of money earned, but there are many fields of science that do not allow direct monetization. Thence, academic publishing output became such a universal measure and is applied all around the world.

"Publish or perish" paradigm becomes a must for researchers who are applying for a research grant or an academic promotion. In the academia, the proxy measures are becoming increasingly important for assessing researchers and advancing their careers (Tian, 2016; or Kun, 2018). A good example of that is an "impact factor" (IF) a scientific citation indexing service produced by the Institute for Scientific Information and originally designed for supporting library acquisitions (Lozano et al., 2012). The IF was originally devised as an advisory system for library purchasing decisions but after several decades it has progressed into an assessment system of scientific productivity of individual researchers and academic institutions widely used in many fields (Heckman \& Moktan, 2018). The "impact factor chase" has become the essence of academic careers in many countries but often leads to the attempts to game with publishing metrics.

Web of Science (also known as the "Web of Knowledge") created by Intellectual Property and Science business of Thomson Reuters became the world's first widely-recognized and acknowledged scientific citation indexing service database. In the end of the 1990s and 2000s, Web of Science became the quintessence of academic metrics and publishing in a journal indexed in it became very prestigious in quite a number of countries (Oswald, 2007). In 2016, it was sold to Clarivate Analytics and continues to operate at the same scale.

One would probably agree that some fields of science are more prolific when it comes to a number of research journals, publications, citations and impact factors. Figure 1 that follows shows the directions of research (based on the most commonly used keywords) for the whole sample of papers indexed in Web of Science throughout 2013-2018.
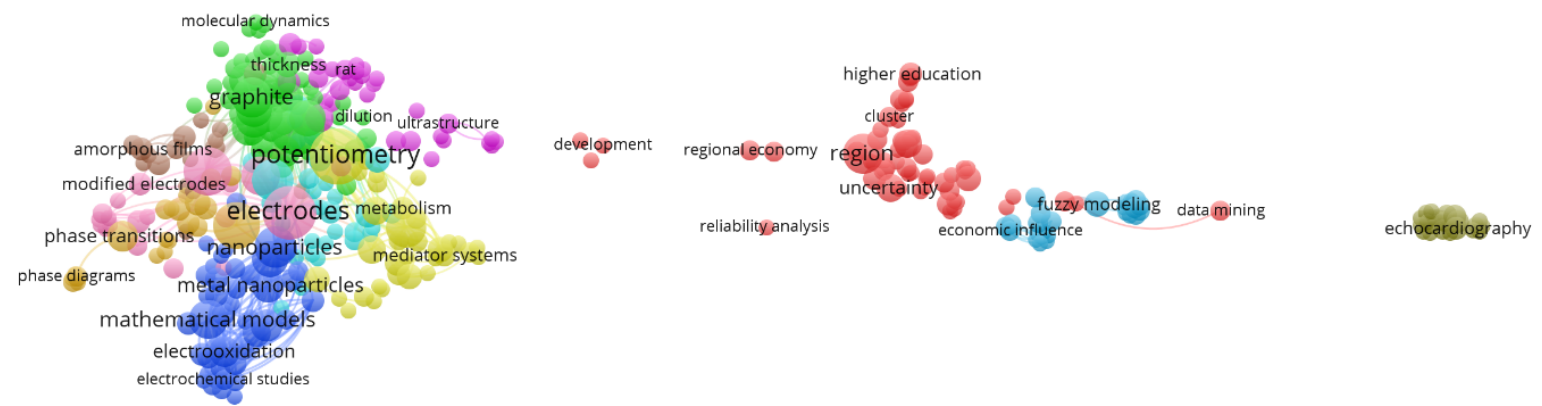

Figure 1. Directions of research by papers indexed in Web of Science (2013-2018) Source: Web of Science (2018)

One can see from the figure above that natural sciences such as physics, biology, or medicine occupy the largest part of the research space. No wonder about that: after all, most of the medical journals are published monthly (in comparison with journals in the fields of social sciences or humanities that are published quarterly) and the world-famous multidisciplinary journals such as Nature or Science are published once a week.

Therefore, when measuring research productivity or, say, a physicist, and an economist, one should always remember that the number of citations and publications she or he is looking at are literally apples and pears. Figure 2 that follows shows the normalized citation impact of documents (papers and articles) indexed in Web of Science. One can see how the metrics for natural and social sciences differ dramatically.

The pressure to publish a lot and quickly led to the Scholarly Open Access (OA) journal publishing model that emerged as the alternative to the large publishing companies which 
controlled the vast share of the academic publishing market. OA model enabled the authors to pay for the publication of their papers once they are peer-reviewed and accepted for publication (so-called "author pays principle").

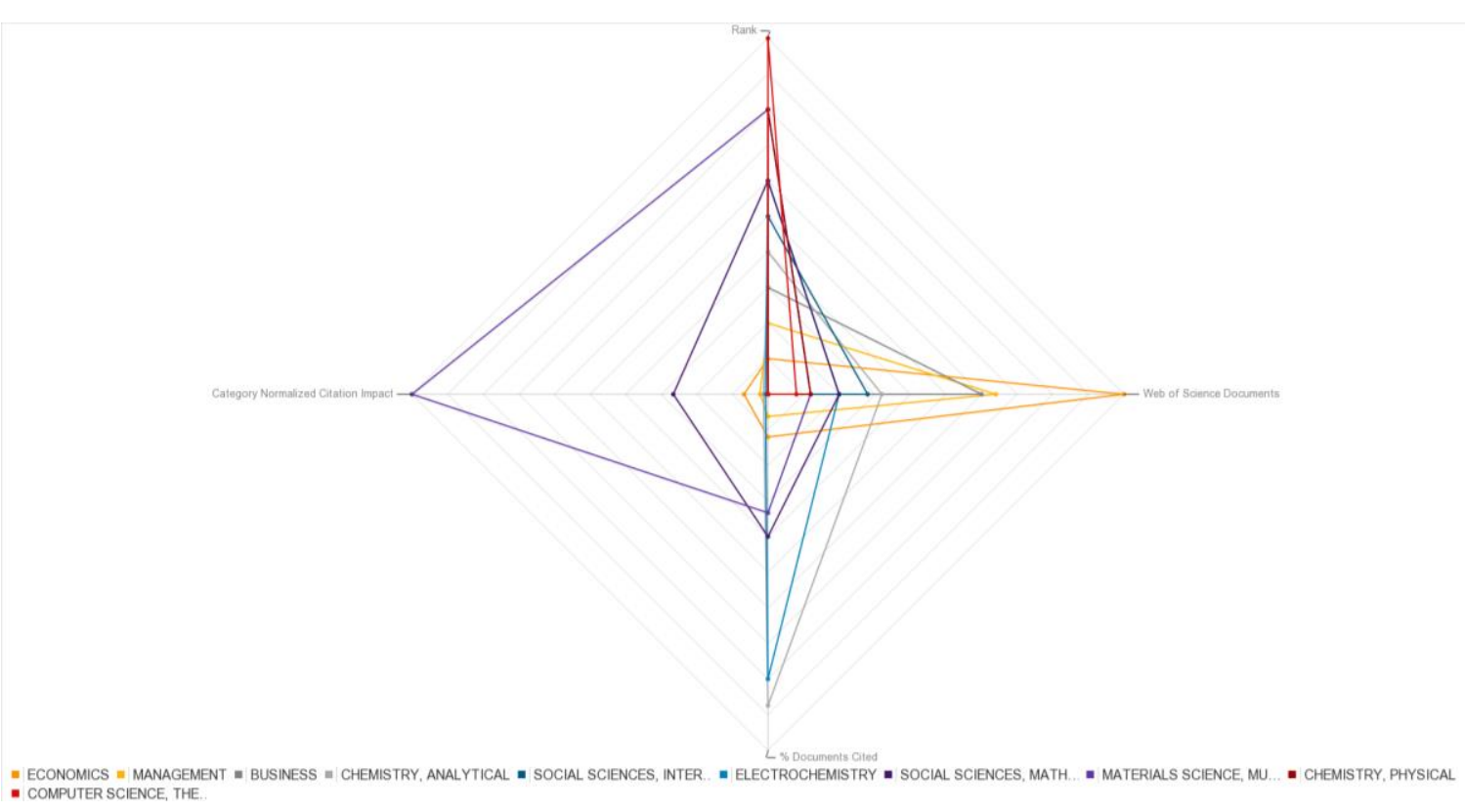

Figure 2. Web of Science (WoS) documents category normalized citation impact (\% of documents cited)

Source: Web of Science (2018)

The rise of OA was inevitable due to the increase in research output and the expansion of the Internet. However, the traditional publishing models seemed to lag behind. One can clearly see that the academic publishing system which was established after WWII is economically highly unsustainable. In general, the system works as follows:

- governments pay the scientists to do their research;

- scientists publish their results in academic journals; and finally,

- governments pay again for the scientific results to be published in academic journals (and to be accessed afterwards through numerous journals indexation databases) (see Strielkowski, 2017).

The scholarly OA became the solution to that economic conundrum. It started with such pioneers as PLOS One journal published by the Public Library of Science since 2006.

Raising pressure to publish coupled with the visibility of every scientist's research productivity on the Internet led to a paradox when speed of publication became an essential asset. Open Access journals offer that speed which leads to the accusations of "questionable" peer-reviewing by the supporters of the traditional publishing models.

The pressure to publish also leads to gaming with metrics. One of the countries which is an interesting case of famous misconducts in academic publishing and gaming with publishing metrics is Brazil. In 2013, a so-called "Brazilian citation scheme" was uncovered by Thomson Reuters (the owner of Web of Science database at the time) which produced a big scandal and led to the expulsion of many Brazilian highly-ranked journals from Web of Science database (Van Noorden, 2013). 
Nevertheless, new metrics and new citation databases come in place. In 2004, a Dutch academic publishing giant Elsevier launched its own abstract and citation database called Scopus (we will discuss it in more detail in Section 4). However, this is not the end of it. In 2017, Elsevier acquired a small Pennsylvania-based data company called Plum Analytics and introduced yet a new digital metric called "PlumX". And most recently, a new initiative and a digital platform called "Publons" emerged as a solution to decreasing numbers of peer reviewers who lacked any incentives to review academic papers free of charge.

\section{PlumX and Publons: Gaming with altmetrics}

Plum Analytics, a scientometrics data aggregating company, was founded in 2012. In 2014, it was acquired by EBSCO and in February 2017 it became a part of Elsevier. The company gathers all the altmetric data for a special purpose to be able to use it to support researchers to answer their questions.

PlumX Metrics on Scopus was designed to offer a new insight into how metrics around research is being used. According to Elsevier, this new metrics would soon become the new standard both for the science funders and for the scientists. Science funders will use PlumX Metrics for monitoring the online environment with the purpose of deciding where they should invest and what research they should support. Scientists will be using the new metrics to justify the return of the research money. Moreover, the metrics can be used to identify the "rising stars" among the early career researchers (Lindsay, 2016).

In August 2017, Scopus and Plum Analytics bibliometricians held a joint webinar entitled "How PlumX Metrics on Scopus help tell the story of your research" (PlumX, 2017). The webinar provided a number of very interesting ideas: First of all, the PlumX metrics project seems to be very ambitious. However, it is still unclear why we need another research metrics. Moreover, it seems that PlumX Metrics is not much different from Google Scholar, an automated Google service that tracks citations and mentioning of academic papers and books from all possible sources. Many scientists wonder that their Google Scholar citations are always higher than Scopus or Web of Science citations. The explanation is simple: Google Scholar uses the machine code to track all possible academic databases as well as blogs, personal websites, Twitter, Facebook, Instagram, etc. It is embedding the Web of Science (a very small and elite database), Scopus (which intersects with the Web of Science) and all possible sources beyond that (Martín-Martín et al., 2018).

Lots of scholars would probably agree that Google Scholar is a very open database and has fuzzy edges (Dorsch et al., 2017; Flatt et al., 2017). Machines are determining what to index and they might index a blog, a personal website, and put it into the Google Scholar citations. On the contrary, Scopus is highly curated and maintains the quality level. Surely, this was true when we were dealing with citations in other Scopus journals and using SCImago and SJR. However, as soon as we are going to count citations and mentions beyond the curated databases, we might run into a problem.

Moreover, it can be shown that PlumX Metrics also provides a competitive advantage to scientists who are more familiar with IT and web technologies and therefore can engage in gaming in social platforms in order to increase the significance of their research (Champieux, 2015; Wong \& Vital, 2017).

The implications of automated Twitter accounts (e.g. bots and cyborgs) and their possible use in politics (e.g. socket puppets and troll factories that are claimed to be used during the recent presidential campaign in the United States), works on gaming in altmetrics represents the new topic in the scientometrics and library information literature (Haustein et al., 2016). 
Moreover, there is Dark Web (or Darknet) that makes it possible to game in the new altmetrics and abuse it through the use of the social media platforms. Dark web represents a small section of the Internet which is encrypted and allows to carry out data transfers and transactions with total anonymity. It was originally designed by the U.S. Navy for the stealth operations but was eventually given to the public and adapted by hackers and all those who seek anonymity on the Internet. The whole think became known to the general public with the story of the Silk Road, a Darknet website that was designed to buy and sell drugs using the tools and precision of Amazon or Craiglist (Maras, 2014).

One can use the Dark Web to boost her or his citation score in the online environment. If one is using Tor browser, she or he is completely anonymous, so the person can create blogs and Twitter accounts claiming to be maintained by different people in different countries. Using these blogs and accounts one can praise her or his research to show that it is more important for the society and the general public than the research of others

Another interesting thing that recently emerged on the academic horizon is Publons. Publons represents a database of peer reviewers linked to the ORCID identification control scheme that encourages reviewers to peer-review academic papers and earn virtual tokens or "publons" (Publons, 2018). In a very short span of time, the initiative found many supporters (e.g. Wiley, Sage, Springer Nature, Cambridge University Press, or MDPI just to name a few). Some universities reportedly started checking the Publon profiles of their new job candidates to see the number of reviews. Although some might say that Publons are currently to complex and require constant Internet connection to work properly, the initiative introduced a novel trend that might be further developed and improved. And this is not to mention that it invented a new way how to lure potential peer reviewers with limited time into reviewing more papers free of charge. With regard to that, one would probably recall the so-called "Tom Sawyer's effect" and the paradox of the construction of value. Once something becomes popular among a large number of people, other people are prepared to sacrifice their time and effort to have it (see Ariely et al., 2006).

All in all, it becomes apparent that introducing the transparent and functional system of peer reviewers' identifications would allow to solve many problems with academic functionality: first of all, it will enable to combat fraudulent publishing (since the absence of peer-review or the "staged" peer-review is, effectively, the only legitimate way to identify these journals and publishers) and to corroborate disputable research outcomes in academic articles. When all reviewers are using a legitimate identification, it would be possible to check whether any given article was really peer-reviewed and by whom. This is becoming relevant in the light of the historically first U.S. court order issued by a state judge in California which demanded the academic publisher to identify the anonymous peer reviewers of the 2013 sport medicine journal article (Han, 2018). Peer reviewers' confidentiality has always been the basis of academic publishing even though many academic journals are already using a system when the author can suggest the reviewers during the article submission. Publons platform is going to lure more reviewers into reviewing papers in order to boost their Publons metrics, same as it is with publishing papers and tracking citations in academic journals.

\section{Measuring academic productivity}

Between 1945 and 1991, United States and Soviet Union used to be world's global superpowers which struggled and competed with each other for the domination of their leading ideology, capitalism and communism. The areas of this competition ongoing for almost five decades arms race, food production, space technologies, but also research, development, and science. Rivalling superpowers enviously monitored the scientific publications of each other, 
even though it was forbidden for scientists to publish in "enemy's" journals and severe persecutions were often imposed (Polyak 2002). However, even though the Cold War was a gruesome business, it leads to the unprecedented investments of money and efforts into the space technologies and resulted in the first man in space and first man on the moon. Conquering of space would never be so prioritized and financially supported even though private companies such as Elon Musk's Tesla are trying to prove the opposite.

Borjas and Doran (2012) describe a case study of Soviet mathematicians and show that after the collapse of the Soviet Union, over 1000 Soviet mathematicians migrated to other countries, mostly to United States. Many of them obtained tenured academic positions in top U.S. universities' mathematical departments (Google founder Sergey Brin's father was one of them) which led to a large influx of mediocre U.S. mathematicians out of the universities and into the financial business (for example at the Wall Street), which, in turn, led to the invention of innovative mathematical models in banking and finance and caused World's Financial Crisis of 2008 .

Grancay et al. (2017) show that Central and Eastern European economists fall behind their Western colleagues and are struggling with their increasing academic publishing requirements. With regard to this, Guskov et al. (2018) marks the growth of the publication activity in top Russian universities in 2010-2016 in their pursuit of making at least 5 Russian universities to enter the top 100 leading international universities according to the global universities rank. However, one can see that now, more than 27 years after the end of the Cold War, Russia is clearly outperformed by the United States in the number of publications (see Figure 3).

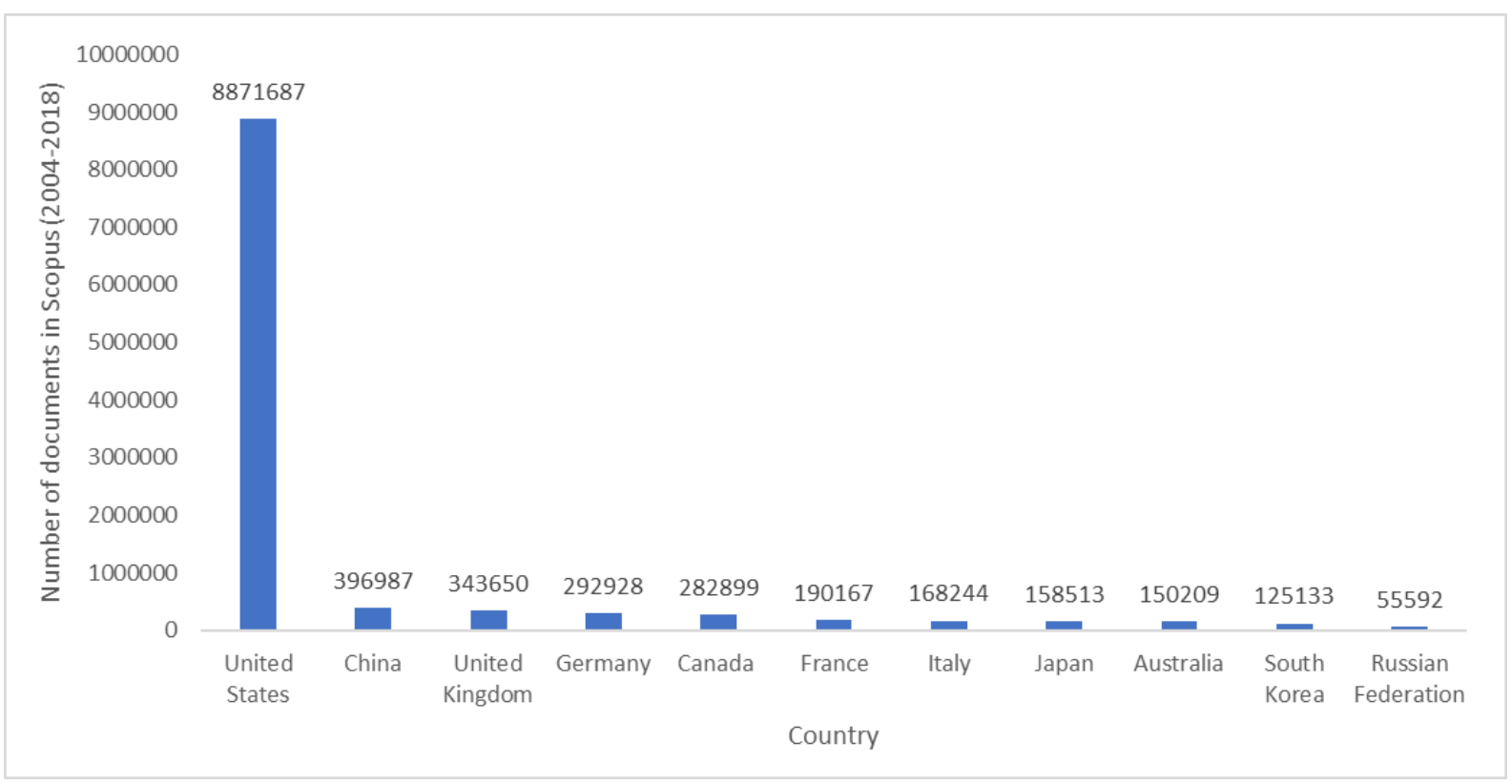

Figure 3. Number of documents in Scopus database by countries (Top 10 countries and Russian Federation, 2004-2018)

Source: Scopus (2018)

It is also interesting to compare the research and academic productivity of the major research institutions. For the purpose of this research, we selected a case of Academies of Sciences of the three counties. Our choice is pre-determined by the fact that Academies of Sciences are those institutions which focus entirely on research and publishing and are typically 
not required to conduct lectures on a daily basis. Thence, their research output (divided by fields) might represent a good proxy for measuring the scientific output of a given country.

We run a comparative analysis of the publication activity of the Chinese Academy of Sciences (Beijing, China), Russian Academy of Sciences (Moscow, Russia), and the Czech Academy of Sciences (Prague, Czech Republic) by disciplines (the United States was not used due to the fact that there are multiple Academies of Sciences in the country and also because most of the U.S. academics use their universities affiliations when submitting their papers into research journals). The results of our analysis are presented in Figure 4.

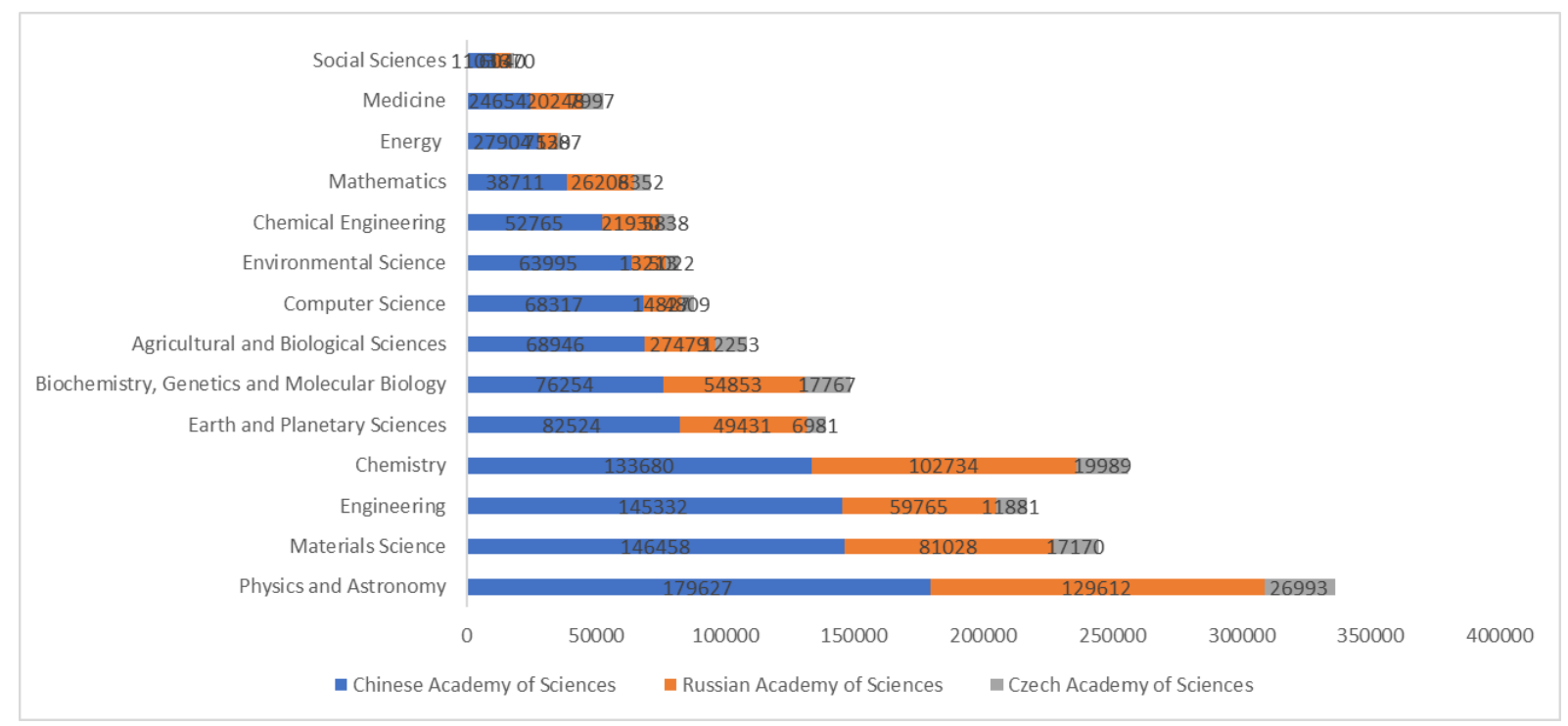

Figure 4. Academic productivity for the Academies of Sciences (China, Russian Federation and Czech Republic), documents indexed in Scopus

Source: Scopus (2018)

All in all, it becomes clear that China is outperforming the remaining two countries in terms of documents published in Elsevier's Scopus database since its initiation in 2004. However, the fields of science that are perfected in various countries are different. All three countries in question yield the largest numbers of research publications in Physics and Astronomy followed by Materials Science, Engineering, or Chemistry. Social science, for example, constitute only a small share of research output in each of the countries in question.

\section{Implications for the future: Plan S for academic publishing}

Moreover, in the light of the above results and outcomes, we would like to comment the recent changes in academic functionality and efficiency in the light of Web of Science, once the world's highly-ranked bibliometric database, losing its importance as well as its customers and markets to Elsevier's Scopus. Furthermore, we discuss the implications that will be brought about by the recent initiative of Science Europe, a group of national research funders from eleven European Union countries that forged "Plan S", a requirement for public universities and research institutions to publish their work only in Open Access journals by 2020.

In our view, Plan $S$ would change the academic publication market as we know it, luring away the customers from the traditional subscription-based journals and world's top publishers with the largest shares of academic literature (the so-called "Big Five" lead by Elsevier and Springer Nature). We also discuss the potential of preprints, a new form of disseminating 
academic research in a form or non-peer reviewed papers available online for free access and download.

In addition, our paper assesses the academic output of top researchers in multiple fields of science in different countries in order to draw comparisons and find factors that influence global research careers. We are contemplating whether the big data analysis based on the data obtained from Elsevier's Scopus database for a plethora of countries and research domains would help the scientific community to categorize the links between global research productivity and various internal and external factors.

\section{Conclusions and discussions}

Overall, one can see that research functionality and academic publishing are becoming more complex and diverse in our digital age. New technologies provide new possibilities (e.g. to check anyone's h-index or citation count) in an instant, yet they also create a space for gaming with (alt)metrics. Never ever before in the history of science was it so commercialized and marketed. Recent developments resulted in usurpation of academic publishing by large corporations who use consumer marketing and introduce new products just like any business company would do.

Nowadays, academic functionality depends on a number of often contradicting indices, rules, platforms, citation databases and metrics. It takes a real expert to obtain a good understanding of all of them and to play the academic game at a decent level.

What more, it appears that the next step in research functionality and academic publishing will be artificial intelligence and Big Data. Not only they will be used for collecting, processing and analysing the data for research papers, just like we used to do in the good old days with the help of Statistics and Econometrics, but machines and algorithms will also monitor and assess the performance of both individual researchers and research institutions. Once they are in place, no one will be able to game with altmetrics.

\section{References}

Agarwal, A., Durairajanayagam, D., Tatagari, S., Esteves, S. C., Harlev, A., Henkel, R., ... \& Majzoub, A. (2016). Bibliometrics: tracking research impact by selecting the appropriate metrics. Asian journal of andrology, 18(2), 296-309. https://dx.doi.org/10.4103\%2F1008-682X.171582

Ariely, D., Loewenstein, G., \& Prelec, D. (2006). Tom Sawyer and the construction of value. Journal of Economic Behavior \& Organization, 60(1), 1-10. https://doi.org/10.1016/j.jebo.2004.10.003

Banks, D. (2018). Thoughts on publishing the research article over the centuries. Publications, 6(1), 10. doi: 10.3390/publications6010010

Borjas, G. J., \& Doran, K. B. (2012). The collapse of the Soviet Union and the productivity of American mathematicians. The Quarterly Journal of Economics, 127(3), 1143-1203. https://doi.org/10.1093/qje/qjs015

Brogaard, J., Engelberg, J., \& Parsons, C. A. (2014). Networks and productivity: Causal evidence from editor rotations. Journal of Financial Economics, 111(1), 251-270. https://doi.org/10.1016/j.jfineco.2013.10.006

Brotherton, C. A., Naz, S., Zaidi, S. S. E. A., Dennis, A. F., Hämäläinen, A., Strielkowski, W., ... \& Li, Y. (2018). NextGen VOICES: A postdoc's purpose. Science, 360(6384), 26-27. https://doi.org/10.1126/science.aat6008

Ceci, S. J., \& Peters, D. P. (1982). Peer review: A study of reliability. Change: The Magazine of Higher Learning, 14(6), 44-48. https://doi.org/10.1080/00091383.1982.10569910

Champieux, R. (2015). PlumX. Journal of the Medical Library Association, 103(1), 63-64. https://doi.org/10.3163/1536-5050.103.1.019 
Chigisheva, O., Soltovets, E., \& Bondarenko, A. (2017). Functional foreign language literacy for global research career development: Analysis of standardized open-ended interview responses. XLinguae, 10(4), 138-153.

Dorsch, I., Askeridis, J. M., \& Stock, W. G. (2017). Truebounded, Overbounded, or Underbounded? Scientists' Personal Publication Lists versus Lists Generated through Bibliographic Information Services. Publications, 6(1), 7. https://doi.org/10.3390/publications6010007

Flatt, J. W., Blasimme, A., \& Vayena, E. (2017). Improving the measurement of scientific success by $\begin{array}{llll}\text { reporting a self-citation index. } & \text { Publications, }\end{array}$ https://doi.org/https://doi.org/10.3390/publications5030020

Grancay, M., Vveinhardt, J. \& Sumilo, E. (2017). Publish or perish: how Central and Eastern European economists have dealt with the ever-increasing academic publishing requirements 2000-2015. Scientometrics, 111(3), 1813-1837. https://doi.org/10.1007/s11192-017-2332-z

Guskov, A.E., Kosyakov, D.V., \& Selivanova, I.V. (2018). Boosting research productivity in top Russian universities: the circumstances of breakthrough. Scientometrics, 117(2), 1053-1028. https://doi.org/10.1007/s11192-018-2890-8

Han A. (2018). Judge order unmasking of anonymous peer reviewers. Science, 359(6375), 504-505. https://dx.doi.org/10.1126/science.359.6375.504

Haustein, S., Bowman, T. D.; Holmberg, K., Tsou, A., Sugimoto, C. R., Larivière, V. (2016). Tweets as impact indicators: Examining the implications of automated "bot" accounts on Twitter. Journal of the Association for Information Science and Technology, 67(1), 232-238. https://doi.org/10.1002/asi.23456

Heckman, J. J., \& Moktan, S. (2018). Publishing and promotion in economics: the tyranny of the top five (No. w25093). National Bureau of Economic Research.

Himmelstein, D. S., Romero, A. R., Levernier, J. G., Munro, T. A., McLaughlin, S. R., Tzovaras, B. G., \& Greene, C. S. (2018). Sci-Hub provides access to nearly all scholarly literature. eLife, 7, e32822. https://dx.doi.org/10.7554/eLife.32822

Jankurová, A., Ljudvigová, I., \& Gubová, K. (2017). Research of the Nature of Leadership Activities 1. Economics \& Sociology, 10(1), 135-151. DOI: 10.14254/2071-789X.2017/10-1/10

Kun, Á. (2018). Publish and Who Should Perish: You or Science?. Publications, 6(2), 18. https://doi.org/10.3390/publications6020018

Lindsay, J. M. (2016). PlumX from plum analytics: not just altmetrics. Journal of Electronic Resources in Medical Libraries, 13(1), 8-17. https://doi.org/10.1080/15424065.2016.1142836

Lozano, G. A., Larivière, V., \& Gingras, Y. (2012). The weakening relationship between the impact factor and papers' citations in the digital age. Journal of the American Society for Information Science and Technology, 63(11), 2140-2145. https://doi.org/10.1002/asi.22731

Maras, M. H. (2014). Inside Darknet: the takedown of Silk Road: Marie-Helen Maras reports on the unexplored underworld of cyberspace. Criminal Justice Matters, 98(1), 22-23. https://doi.org/10.1080/09627251.2014.984541

Martín-Martín, A., Orduna-Malea, E., Thelwall, M., \& López-Cózar, E. D. (2018). Google Scholar, Web of Science, and Scopus: a systematic comparison of citations in 252 subject categories. Journal of Informetrics, 12(4), 1160-1177. https://doi.org/10.1016/j.joi.2018.09.002

Ortega, J. L. (2018). The life cycle of altmetric impact: A longitudinal study of six metrics from PlumX. Journal of Informetrics, 12(3), 579-589. doi: 10.1016/j.joi.2018.06.001

Oswald, A. J. (2007). An examination of the reliability of prestigious scholarly journals: evidence and implications for decision-makers. Economica, 74(293), 21-31. https://doi.org/10.1111/j.14680335.2006.00575.x

PlumX. (2017). How PlumX Metrics on Scopus help tell the story of your research. PlumX and Scopus webinar. Available online: https://www.brighttalk.com/service/player/enUS/theme/default/channel/13703/webcast/271407/play

Polyak, B. T. (2002). History of Mathematical Programming in the USSR: Analyzing the Phenomenon. Mathematical Programming, 91 (3), 401-416. https://doi.org/10.1007/s101070100258 
Publons. (2018). Available online: https://publons.com/home. Accessed 27 November 2018

Scopus (2018). Scopus journal indexation database. Available online: www.scopus.com.

Starbuck, E., \& Purtee, S. (2017). Altmetric scores: short-term popularity or long-term scientific importance. Digital Library Perspectives, 33(4), 314-323. https://doi.org/10.1108/DLP-012017-0005

Strielkowski, W. (2017). Will the rise of Sci-Hub pave the road for the subscription-based access to publishing databases?. Information Development, 33(5), 540-542. https://doi.org/10.1177/0266666917728674

Strielkowski, W., \& Chigisheva, O. (2018). Social, Economic, and Academic Leadership for Sustainable Development of Business and Education in the Future: An Introduction. In Leadership for the Future Sustainable Development of Business and Education(pp. 3-8). Springer, Cham. https://doi.org/10.1007/978-3-319-74216-8_1

Sugimoto, C. R., Work, S., Larivière, V., \& Haustein, S. (2017). Scholarly use of social media and altmetrics: A review of the literature. Journal of the Association for Information Science and Technology, 68(9), 2037-2062. https://doi.org/10.1002/asi.23833

Tian, M., Su, Y., \& Ru, X. (2016). Perish or publish in China: Pressures on young Chinese scholars to publish in internationally indexed journals. Publications, 4(2), 9. https://doi.org/10.3390/publications4020009

Valickas, A., Raišienè, A. G., \& Arimavičiūtè, M. (2017). Leadership competences for the excellence of municipalities' strategic management. Journal of International Studies, 10(4), 131-142. doi:10.14254/2071-8330.2017/10-4/10

Van Noorden, R. (2013). Brazilian citation scheme outed. Nature, 500(7464), 510-511. https://doi.org/10.1038/500510a

Web of Science (2018). Web of Science journal indexation database. Retrieved from www.webofknowledge.com

Wong, E.Y., \& Vital, S.M. (2017). PlumX: a tool to showcase academic profile and distinction. Digital Library Perspectives, 33(4), 305-313. https://doi.org/10.1108/DLP-12-2016-0047 